\title{
FONEMAS FINALES EN EL CONSONANTISMO PUERTORRIQUEÑO
}

Hace unos tres años tuve la suerte de pasar un año completo en la isla de Puerto Rico, como profesor visitante de la Facultad de Estudios Generales de la Universidad. Además de dar clases de inglés como idioma extranjero, dirigí una serie de programas de televisión y de radio dedicados a la enseñanza de ese idioma. Se me brindó así una excelente oportunidad para observar los dos idiomas y el bilingüismo puertorriqueño. (Con anterioridad, había enseñado inglés durante muchos años a alumnos italianos e hispanoamericanos, pero nunca había tenido alumnos de Puerto Rico ni de otras regiones del Caribe).

El estudio del inglés se inicia en el primer año de la escuela primaria, de manera que todo estudiante puertorriqueño, al ingresar en la Universidad, ha cursado doce años de inglés como idioma extranjero. Por eso me sorprendí mucho la primera vez que uno de mis alumnos me dirigió la palabra de este modo: [míhtel / ái đõ há di tãi tu ehtódi yéhtelde / so ái gí yú di hõwol di néh tãi//]. A pesar de mi buen oído, me costó trabajo entenderle. Después de acostumbrarme un poco a esta mezcla fonética, supe que lo que el alumno había tratado de decirme era: "Mister", I don't have the time to study yesterday, so I give you the homework the next time". Para mí, esto representaba una experiencia lingüística totalmente nueva, y comprendí desde un principio que tendría que examinar con mucho detenimiento un sistema fonético capaz de producir un inglés tan líquido.

Evidentemente, todo se reducía a un problema de consonantes finales. En los círculos lingüísticos se ha hablado siempre del consonantismo débil que caracteriza al español del Caribe, pero nunca se ha detallado esto de manera que muestre gráficamente las diferencias estructurales exactas, en posición final, entre el consonantis-

1 [míhtel] (Mister), fórmula de respeto, tanto en el español como en el inglés de Puerto Rico, reservada en un principio para los llamados "continentales" (norteamericanos del continente, a diferencia de los ciudadanos norteamericanos de la Isla), pero que ahora se ha hecho general. En el habla de los estudiantes de todos los niveles es casi el único modo de dirigirse al profesor; alterna con [tíĉel] (teacher) y corresponde al uso de la palabra maestro en México. 
mo del castellano, el del español del Caribe, el de algunas hablas de las altiplanicies hispanoamericanas (como el español de México, por ejemplo), y, por otro lado, el del inglés.

Fue menester, en primer lugar, investigar a fondo el habla puertorriqueña actual para descubrir los cambios que pudiera haber sufrido durante los treinta años que han pasado desde el estudio ejemplar que de ella hizo don Tomás Navarro². Los resultados son éstos:

I) Todavía se oye en Puerto Rico la [a] palatal, que se atrasa para indicar la ausencia de una -s perdida en la pronunciación: [pąhta] 'pasta', pero [má] 'más'. Esta palatalización tiene valor fonemático (significante), pues establece una distinción entre las formas verbales de la segunda y tercera persona del singular de la primera conjugación [õde báa (tú) contra [õde bá] (usted).

2) Las vocales tónicas é, ó todavía suelen abrirse más que en la mayoría de las demás hablas hispánicas, especialmente en sílaba libre, por una parte: [pęso], [pęlo], [dędo], y por otra, para significar la oposición fonemática de dos palabras que de otro modo serían idénticas después de perderse la $s$ final de una de ellas ${ }^{3}:$ [pjé] "pie" $\sim$ [pjée 'pies', [bé] (usted) —[béc] (tú), [djó] 'dio' — [djó] 'Dios', etc.

3) La $f$ sigue siendo regularmente bilabial: [ $\phi$ ásil] 'fácil', [ $\phi$ rénte],

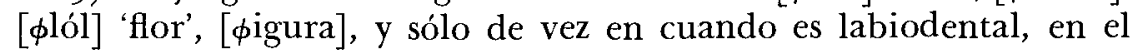
habla culta. La aspiración de $h$ procedente de $f$ es aún muy común: [hwíl] 'huir', [hũdíl] 'hundir', [hasél] 'hacer', [hablál]. Toda $j$, por cierto, recibe este mismo tratamiento faríngeo y glotal, en vez del velar: [káha] 'caja', [óho], [ího].

4) Cuando don Tomás Navarro hizo su estudio, se podían encontrar en Puerto Rico casi todos los tipos de $s$. La variante que hoy se oye con muchísima mayor frecuencia que cualquier otra es la coronal dentoalveolar plana, o sea el mismo tipo que se encuentra en Santo Domingo, en Colombia y en todas las Antillas, en las costas y en los estados norteños de México, en Nuevo México y en gran parte de Andalucía ${ }^{4}$. Esta $s$ se articula con la corona de la lengua en un punto situado entre los alvéolos y los incisivos superiores,

2 Tomás Navarro, El español en Puerto Rico, Río Piedras, 1948. (Las investigaciones del autor en la Isla se remontan a 1927-28).

3 Fenómeno que Navarro llama "desdoblamiento vocálico": véase su artículo "Desdoblamiento de fonemas vocálicos", $R F H, 1$ (1939), 165-167.

* Un estudio más amplio de los distintos tipos de $s$ que se dan en el mundo hispánico puede verse en J. H. Matluck, La pronunciación en el español del Valle de México, México, 1951, pp. 72-74. La $s$ coronal del Norte de México no suele relajarse como la de los otros lugares mencionados. Además de la coronal plana, se halla en Puerto Rico la $s$ predorso-dentoalveolar convexa (común en la altiplanicie mexicana y en gran parte de Hispanoamérica), la $s$ ápicodental y la $s$ ápicoalveolar cóncava (como la de Córdoba [España], semejante a la castellana, pero menos apical, menos cóncava y menos grave, y sin el matiz palatal que a veces tiene la castellana). 
pero es más bien alveolar. La punta de la lengua se apoya entre los incisivos superiores y los inferiores. Por eso adquiere a menudo un timbre dento-interdental, cosa que ha hecho suponer a algunos investigadores que en Puerto Rico existe el ceceo ${ }^{5}$.

La única $s$ puertorriqueña que no desaparece ni se aspira es la inicial (de palabra o de sílaba): pasa, peso, seso, siete, etc. En final de sílaba se aspira: cuehte lo que cuehte, pehcal 'pescar', pehtaña, rehpeto, etc. En posición final absoluta (ante pausa) se elimina por completo, al igual que toda otra consonante con excepción de /1/ y /n/: [dó] 'dos', [trę́] 'tres', [djó] 'Dios', [hamá] 'jamás', [bjélne] 'viernes'. La $s$, en esta posición, sólo recobra su aspiración en fonética sintáctica cuando no sigue una pausa (es aún final de palabra, pero ya no final absoluta): [dóh_i dó] 'dos y dos', [tréh i tréc], [djóh é grãde] 'Dios es grande', [loh_ótro] 'los otros', [hamáh_e bíhto] 'jamás he visto', [bjélneh e $\phi$ jéhta] 'viernes es fiesta'.

5) La igualación de $l$ y $r$ en un solo fonema / / es fenómeno cada vez más arraigado. Navarro (op. cit., p. 8o) hizo notar la tendencia de los habitantes de la parte occidental de la Isla -y en especial, la región del Sudoeste, alrededor de Mayagüez- a igualarlas en un fonema $/ \mathrm{r} /:$ farda 'falda', sarto, arguno, y afirmó que la tendencia opuesta predominaba en el Oriente y sobre todo en el Noroeste: puelta 'puerta', cuelpo, talde. Yo pude observar una fuerte propagación del fonema /1/, aun en el Oeste y el Sudoeste, donde ahora es casi general: [la lú bélde] 'la luz verde', [la kálne] 'la carne', [háse múco kalól bel-lá $\uparrow$ ] 'hace mucho calor, ¿verdad?'; Rubén del Rosario, lingüista puertorriqueño, afirma lo mismo en un artículo escrito en $1946^{6}$.

6) La $r r$ múltiple $/ \overline{\mathbf{r}} /$ se encuentra todavía en sus tres realizaciones fonéticas: vibrante alveolar, fricativa velar, y mixta; de ellas, la más común es, con notable diferencia, la fricativa velar sorda [x]: [péxa] 'perra', [cáxo] 'carro', [ $\phi$ exokaxíl] 'ferrocarril'. Para quien visite la Isla, éste es el más desconcertante de todos los fenómenos lingüísticos puertorriqueños. Al oír [ehtá xóto], alguien que haya estado en México puede pensar que se habla de un joto ('marica, homosexual'), cuando en realidad se dice que algo está roto; [xamõ-

5 Navarro, op. cit., p. 69, sugiere que es otra $s$, ápicodental, la que da la impresión de ceceo. Tiene razón, pero será bueno aclarar I) que estas dos eses pueden oírse en el habla de una misma persona, y 2) que suele tener el timbre ceceante sólo si el punto de contacto (ya con la corona, ya con el ápice) se adelanta y se hace más dental que alveolar.

6 Rubén del Rosario, La lengua de Puerto Rico, 2a ed. revisada, San Juan, 1956, p. 7: “...el debilitamiento de la $r$ terminal, que se llega a pronunciar en todas partes de la Isla como $l$ o con un sonido intermedio de timbre indeciso: puelta, vendel...; las formas con $l$ se oyen en boca de algunos locutores, conferenciantes y maestros". 
síto] nos hace pensar en una rebanada de jamón, pero resulta que se trata de un chiquillo llamado Ramón. Esta proximidad de jota y erre ("la hota y la eje") siguió siendo causa de confusión para mí durante todo el año que pasé en Puerto Rico: [éh ung áho] quiere decir 'es un ajo', mientras que [éh un háxo] significa 'es un jarro'. El platillo nacional de Puerto Rico no está hecho de frijoles con ajo, sino, claro está, de frijoles con arroz: [axó i habiĉwéla] 'arroz y habichuelas'. Y [la lú xóha] es 'la luz roja'.7

7) En cuanto al sonido palatal / $\hat{\mathbf{c}} /$, el modo de articulación puertorriqueño resulta algo distinto del de otros dialectos: es más bien adherente que africado, y en él tiene más relieve el elemento oclusivo que el fricativo: leche, noche, cuchara, etc.

8) La $n$ velar [y] es absoluta y positivamente la única variante alofónica en posición final absoluta (ante pausa): [kalbón] 'carbón', [xasóy] 'razón', [páy], [hóber], [çaketóy]. No se oye otra variante alguna, cualquiera que sea el nivel económico, social $o^{\circ}$ cultural de los hablantes. Los puertorriqueños son incapaces, en su gran mayoría, de percibir esta variante, ni en su propia habla ni en la de sus compatriotas, y por eso muchos de ellos niegan rotundamente que pronuncien la $n$ de esa manera. Navarro, poco inclinado a hacer afirmaciones categóricas a no ser que esté completamente seguro de su tesis, dice de este fenómeno: "La $n$ velar, que en otros países compite con la alveolar en posición final de grupo, ha ganado en Puerto Rico el dominio de toda la Isla. Las personas examinadas dijeron uniformemente la $n$ velar en las palabras experimentales... La $n$ velar se manifiesta en las personas instruidas con la misma regularidad que entre los campesinos iletrados" (op. cit., p. 101). En efecto, tan arraigado y constante es este uso, que la calidad velar de la nasal sirve para señalar el contraste significativo entre el enlace, por una parte, y la transición abierta (plus juncture) por otra: /ún obíyo/ /ú nobíyo/ 'un ovillo', 'un novillo',/en ágwa/ /enágwa/ 'en agua', 'enagua', /en óho/ /enóho/ 'en ojo', 'enojo'.

7 El origen del fenómeno (la $r r$ velar) sigue siendo oscuro. Puerto Rico es el único lugar de habla española en que se da como hábito lingüístico de índole colectiva. ¿Se deberá a influencia del sustrato? Los indios arahuacos que habitaban la Isla a la llegada de los españoles (y que desaparecieron muy pronto) hablaban taino, idioma hablado también en Santo Domingo y en Cuba. Esta lengua, que sin duda debió desaparecer de Puerto Rico entre los siglos xvilI y xix, ha dejado sus huellas en nombres de ríos, plantas, frutas, animales, etc. Ahora bien, en el sistema fonemático del taino había una vibrante simple (en palabras como ture, guaraguao, múcaro, etc.), pero no existía ninguna vibrante múltiple. Por eso, como hipótesis provisional, a falta de informes más completos, se supone que el sonido fricativo velar sordo [x] que se oye en Puerto Rico puede ser el resultado de la acomodación de la $r r$ castellana al fonetismo nativo, bajo alguna influencia especial del sistema fonético boricua. (Cf. NAVARRO, op. cit., pp. 9495). 
9) Navarro no advirtió nada que le hiciera pensar que las vocales nasalizadas ofrecieran, en el habla puertorriqueña, un desarrollo más avanzado que en otros dialectos. Puede que sea fenómeno de reciente evolución, pero, según mis observaciones, la consonante nasal en posición final de sílaba desaparece muy a menudo, dejando nasalizada la vocal anterior: [kõsegíl] 'conseguir', [êtõse] 'entonces'.

El inglés americano posee, en posición final de palabra, 21 fonemas consonánticos: sup, sub, let, led, luck, lug, rich, ridge, half, have, cloth, clothe, his, hiss, fish, rouge, tell, hair, sum, sun, sung, cada uno de los cuales desempeña una función distintiva. El castellano, en cambio, tiene sólo 6 fonemas consonánticos finales, con un total de 7 variantes alofónicas de importancia 9 . El habla de la altiplanicie de México - para referirme a otra zona hispanoamericana que conozco muy de cerca- tiene 5 fonemas consonánticos, con un total de 5 variantes alofónicas. Pues bien, el habla de Puerto Rico posee sólo 2 fonemas consonánticos en posición final, con un total de 3 variantes alofónicas, una de las cuales es el cero fonético, con lo que no restan sino 2 sonidos consonánticos finales: lateral [1] y velar [j]. A este número tan exiguo de consonantes finales podemos añadir, en casos de fonética sintáctica, el sonido glotal [h] ante palabra que empieza con vocal: [loh ótro] 'los otros'10. Veámoslo más claramente en un cuadro comparativo:

Fonemas finales de palabra y sus variantes alofónicas

\begin{tabular}{cccccc}
\multicolumn{2}{c}{ castellano } & \multicolumn{2}{c}{ mexicano } & \multicolumn{2}{c}{ puertoriqueño } \\
fonemas & variantes & fonemas & variantes & fonemas & variantes \\
$/ \mathrm{d} /$ & {$[\mathrm{d}] \mathrm{o}[\mathrm{-}]$} & $/ \mathrm{d} /$ & {$[\mathrm{d}]$} & $/-/$ & {$[-]$} \\
$/ \mathrm{s} /$ & {$[\mathrm{s}]$} & $/ \mathrm{s} /$ & {$[\mathrm{s}]$} & $/-/$ & {$[-]$} \\
$/ \theta /$ & {$[\theta]$} & $/ \mathrm{s} /$ & {$[\mathrm{s}]$} & $/-/$ & {$[-]$} \\
$/ \mathrm{r} /$ & {$[\mathrm{r}]$} & $/ \mathrm{r} /$ & {$[\mathrm{r}]$} & $/ 1 /$ & {$[1]$} \\
$/ \mathrm{l} /$ & {$[\mathrm{l}]$} & $/ \mathrm{l} /$ & {$[1]$} & $/ 1 /$ & {$[\mathrm{l}]$} \\
$/ \mathrm{n} /$ & {$[\mathrm{n}] \mathrm{o}[\mathrm{n}]$} & $/ \mathrm{n} /$ & {$[\mathrm{n}]$} & $/ \mathrm{n} /$ & {$[\mathrm{y}]$} \\
\hline 6 & $\frac{7}{7}$ & $\frac{5}{5}$ & $\frac{5}{2}$ & $\frac{1}{2}$
\end{tabular}

8 Del total de 24 fonemas consonánticos del inglés, /h/ no ocurre nunca en posición final; $/ \mathrm{y} / \mathrm{y} / \mathrm{w} /$ sí se dan en esa posición, pero con valor más bien vocálico.

${ }^{9}$ Juzgo inútil y contraproducente incluir aquí variantes como la [d] oclusiva (que aparece en esta posición con poquísima frecuencia), las muchas variantes de /r/ en posición final de grupo, o las pocas de /l/. Tampoco incluyo [z] y [z] sonoras (las mejores, haz dos) que, por aparecer en esta posición únicamente ante palabra que comienza con consonante sonora (en fonética sintáctica), pertenecen más bien a la categoría de final de sílaba, de que trataré en seguida. Tampoco considero como variante digna de atención la velar [x], que aparece en posición final en una sola palabra de uso común: reloj.

10 Esta $s$ final seguida de una palabra que empieza con vocal se encuentra, 


\section{Ejemplos}

castellano: [berđáđ], [séđ] (o [berđá], [sé])

mexicano: [berđáđ], [séđ]

puertorriqueño: [bel-lá], [sé]

$/ \mathrm{s} /$

castellano: [xamás], [bjérnes]; *[los ótros] ${ }^{11}$

mexicano: [xamás], [bjérnes]; *[los ótros]

puertorriqueño: [hamá], [bjélne]; *[loh_ótro]

castellano: [krú $\theta],[\mathrm{lú} \theta] ;$ * [á $\theta$ álgo]

$|\theta|$

mexicano: [krús], [lús]; *[ás_álgo]

puertorriqueño: [krú], [lú]; *[áh_álgo]

$/ \mathrm{r} /$

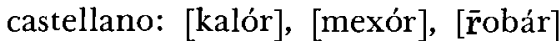

mexicano: [kalór], [mexór], [robár]

puertorriqueño: [kalól], [mehól], [xobál]

castellano: [sál], [papél]

mexicano: [sál], [papél]

puertorriqueño: [sál], [papél]

$/ \mathrm{n} /$

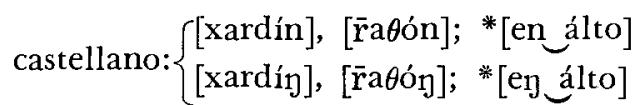

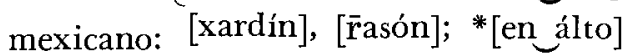

puertorriqueño: [haldín], [xasón]; *[engálto]

En posición final de silaba, el inglés posee 21 fonemas; el mexicano, 7 fonemas y unas 13 variantes alofónicas principales; el castellano, igual número đe fonemas pero con 2 variantes más: $[\theta],[\mathrm{z}]^{12}$;

en realidad, en posición intervocálica (loh otro); pero es distinta de la $s$ intervocálica interior, posición en la que la $s$ mantiene su punto de articulación dentoalveolar: [hasél] 'hacer', [péso] 'peso'. El contraste /h/:/s/ hace posible la distinción entre expresiones como haz habas y asabas: [ah ába] [asába] las aves y la sabes: [lah ábe]—[la sábe], las obras y las sobras: [lah óbra] [la sóbra]. En otras hablas (en la de México, por ejemplo) no se pueden hacer estas distinciones, excepto, en algunas parejas, oor una ligera diferencia de in. tensidad: [às ábas] con acento secundario sobre [às], frente a [asábas].

${ }^{11}$ Los ejemplos precedidos de asterisco son de fonética sintáctica.

12 La posición final de sílaba es la más rica en variantes alofónicas en el castellano y en el mexicano, y aumentaría el total de variantes a unas 20 en cada una de esas hablas. Las que incluyo entre las "principales" son las de gran frecuencia y las que, además, ofrecen diferencias acústicas bastante pronunciadas. Por ejemplo, entre las oclusivas y las fricativas, las sordas frente a las sonoras; entre las nasales, los puntos de articulación bastante apartados uno del otro: bilabial, alveolar, velar. - Entre las muchas variantes que se encuentran en estas hablas y que no incluyo en dicha categoria, están las sibilantes dentales [ş], 
el puertorriqueño, en cambio, 3 fonemas con sólo 3 variantes de im-

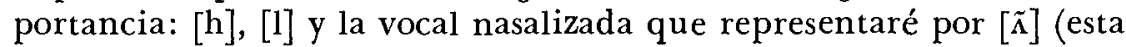
última no tiene valor de consonante).

Fonemas finales de silaba y sus variantes alofónicas ${ }^{13}$

castel
fonemas
$/ \mathrm{b} /$
$\mathrm{d} /$
$\mathrm{g} /$
$\mathrm{s} /$
$\mathrm{r} /$
$/ \mathrm{l} /$
$\mathrm{h} /$

/b/

$/ \mathrm{d} /$

$\lg /$

$/ \mathrm{s} /$

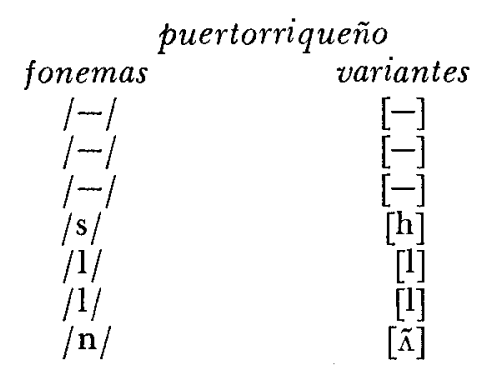

Ejemplos

castellano y mexicano: [ađaptár], [obserbár] puertorriqueño: [ađattál], [oselbál]

castellano y mexicano: [atléta], [admirár] puertorriqueño: [al-léta], [ammirál]

castellano y mexicano: [magnífko], [perféktol puertorriqueño: [mannífiko], [pelfétto]

castellano: [pásta], [dézde], [bi $\theta$ kócoo], [xuzgár] ${ }^{14}$

mexicano: [pásta], [dézde], [biskóĉo], [xuzgár]

puertorriqueño: [páhta], [déhde], [bihkóco], [huhgál]

[z]; las laterales, palatal [1] y dental [1] (las únicas de todo este grupo de variantes secundarias que se dan en el español puertorriqueño); las interdentales, lateral [1] y nasal [n] (estas dos, únicamente en el castellano); las nasales, dental [n] y labiodental [m]; y las numerosas variantes de la $r$ : en el castellano la fricativa sonora [ $x]$, y en el mexicano esta misma y además la fricativa sorda [i̊] y la vibrante sorda $[r]$.

13 Explicaciones acerca de este cuadro: I) en castellano en mexicano, las dos variantes más comunes de cada uno de $\operatorname{los}$ fonemas $/ \mathrm{b} /, / \mathrm{d} /, \mathrm{g} /$ en final de sílaba son las implosivas, sonora y sorda; no empleo símbolos especiales para no complicar aún más el trabajo de la imprenta; 2) en el puertorriqueño, la realización fonética de las letras $b, p, d, t, c, g$ en final de sílaba es, o el cero fonético, o la asimilación completa a la consonante siguiente (véanse los ejemplos, a continuación del cuadro); 3) podría añadirse otro fonema fricativo en final de sílaba (además de /s/): el labiodental /f/; pero su frecuencia es mí. nima (aftosa, oftalm-); en Puerto Rico es bilabial, y se reduce casi a una aspiración; 4) las variantes $[\theta]$, [z] se dan, claro está, sólo en castellano; 5) en el puertorriqueño, la $n$ final de sílaba suele desaparecer, dejando nasalizada la vocal que la precede.

14 Tal vez habría que añadir al castellano el fonema $/ \theta /$ en final de sílaba, con sus dos realizaciones fonéticas, $[\theta]$ y $[z]$; pero como en esa posición nunca aparece dicho fonema en oposición a $/ \mathbf{s} /$, he incluido sus dos variantes alofónicas en el grupo de [s], [z], todas bajo el fonema $/ \mathrm{s} /$. 


$$
\begin{array}{rr}
/ \mathrm{r} / & \text { castellano y mexicano: [kwérpo], [árma] } \\
\text { puertorriqueño: } & {[\mathrm{kwélpo}, \text { [álma] }} \\
/ 1 / & \text { castellano y mexicano: [sálto], [álma] } \\
& \text { puertorriqueño: [sálto], [álma] }
\end{array}
$$

Este repertorio tan limitado de consonantes finales en el habla puertorriqueña no deja de tener muy serias repercusiones. Siendo tan grande, fonemática y fonéticamente, la diferencia cuantitativa entre el puertorriqueño y el castellano -que, quiérase o no, sigue sirviendo de una especie de norma para el habla culta del mundo hispánico (o, cuando menos, como norma de comparación)-, es evidente que, desde el punto de vista de su producción lingüística, el puertorriqueño tropezará con muchas dificultades para comunicar sus ideas a los hablantes de otros países hispánicos, fuera de su zona lingüística inmediata. ${ }^{15}$ Asimismo, la inteligibilidad del español hablado por otros hispanohablantes plantea serios problemas a los puertorriqueños, para los cuales -y especialmente para los de escasa cultura - la intercalación de toda esta variedad de sonidos y fonemas en contornos fonéticos en que ellos suelen oír o el cero fonético o dos o tres sonidos muy distintos de aquéllos, representa un obstáculo casi infranqueable para su comprensión ${ }^{16}$.

Ningún informe sobre el español puertorriqueño sería completo si no aludiese al problema de los anglicismos. Muchos consideran el idioma inglés, no sólo como fuente de corrupción lingüística, sino incluso como una amenaza a la cultura nacional y a la independencia cultural (para no hablair de la independencia política y económica). Es indudable que la influencia norteamericana ha sido tremenda; se han importado nuevas normas culturales que han invadido los terrenos de la organización social, de la jurisprudencia y

\footnotetext{
I5 No quiero decir que sea imposible la comunicación entre esas personas; claro que se entenderán unas a otras; me refiero al grado de inteligibilidad y a la facilidad o dificultad de lograr su grado máximo.

16 Un ejemplo. Durante el año que pasé en Puerto Rico, no hubo casi un solo día en que dejara de saborear los pastelillos a que tan aficionados son los isleños. Cada vez que los pedía pronunciando las [s] y las [r] (dos pastelillos de carne), los dependientes tenían que hacer un gran esfuerzo para entenderme; en cambio, cuando los pedía a su manera ([dó pahtelíyo de kálne]) me los servían inmediatamente. Lo mismo sucedía con dos barquillas de vainilla: [dó balkíya de bainíya] (el cono para helado, barquillo en otras partes, es barquilla en Puerto Rico). Es decir, la insólita pronunciación sibilante de una sola $s$, en vez de la aspiración [h] o del cero fonético [-] habitual, o, en otros casos, la articulación de una sola vibrante [r] en lugar de la esperada lateral [1], puede bastar para confundir a muchos puertorriqueños hasta el grado de que resulta casi imposible hacerse entender de ellos.
} 
de la política, y que han llegado a penetrar hasta en la intimidad de la vida familiar.

El profesor Rubén del Rosario, principal portavoz del grupo de quienes sostienen que el habla de Puerto Rico no muestra una anglicanización mayor que la de otros muchos países influidos por el desarrollo económico angloamericano, critica al grupo de "puristas" por su "preocupación casticista españolizante", que les hace considerar como indeseable toda innovación lingüística, y como incorrecto todo cuanto no se halle registrado en el Diccionario de la Real Academia Española; también rechaza la falsa correspondencia que establecen los "puristas" entre tendencias políticas y actitudes lingüísticas, o sea la idea de que los "estadistas" son tenaces paladines de la enseñanza del inglés y que los "independentistas" son los únicos defensores de la "pureza y castellanidad" del idioma; recuerda, por último, que no es nada raro que una lengua acepte formas extranjeras, ya que esto sucede en todos los idiomas: señala el hecho de que el español tiene más de 4,000 giros árabes y varios miles de galicismos, italianismos, helenismos y germanismos, y de que, por otra parte, el inglés se ha enriquecido hasta el punto de que más del $50 \%$ de su léxico procede del francés, del latín y de otras lenguas ${ }^{17}$.

Navarro replica a estas consideraciones tranquilizadoras del profesor Rosario con respecto a la gravedad de la influencia norteamericana sobre el idioma y la vida de la Isla, advirtiendo que el enriquecimiento del español y del inglés no se llevó a cabo en un ambiente parecido al que prevalece actualmente en Puerto Rico: "Castilla, donde las palabras árabes fueron asimiladas sin detrimento del castellano, era un estado independiente. Inglaterra se encontraba en ese mismo caso desde el siglo $\mathrm{xn}$...., y en la parte de España en que persistió la dominación musulmana, los españoles, después de la natural resistencia, olvidaron su propia lengua y hablaron la de los dominadores" (op. cit., p. 222). En cuanto al bilingüismo, Navarro cree que es imposible pretender que la gente de una cultura definida y elaborada hable con igual perfección dos lenguas distintas ${ }^{18}$. Considera que es preciso tratar de evitar las mezclas e intercambios que en tal situación suelen producirse: "La convivencia de idiomas equivalentes, ventajosa bajo determinados aspectos, es constante amenaza de confusión en el sentimiento lingüístico del

17 Véase la p. 9 de la reproducción de una conferencia dada por el profesor Rosario el 15 de noviembre de 1957 en la Universidad de Puerto Rico. El autor había expuesto anteriormente estas ideas en dos ensayos que aparecieron primero en la prensa de San Juan y después en el libro de I. Ronkícuez Bou, Problemas de lectura y lengua en Puerto Rico, Río Piedras, 1948.

18 Afirmación con la que no podemos estar de acuerdo, en vista de los adelantos logrados durante los últimos años en el campo de la enseñanza de idiomas extranjeros. 
individuo y de la comunidad" (ibid., pp. 224-225). Finalmente -recuerda Navarro (p. 225)-, repetidos estudios confirman la impresión de que la calidad del español hablado por los jóvenes puertorriqueños es notablemente inferior a la de la generación precedente.

Más de treinta años después, al comparar el habla de los jóvenes de hoy con la de las dos generaciones anteriores, se aprecia un notable descenso de nivel, en el cual la distancia más grande es la que separa a la generación actual de la inmediatamente anterior. Estoy de acuerdo, en términos generales, con Navarro y los "independentistas". Pero al fin y al cabo, según algunos de los colegas que tuve en Río Piedras, yo soy un "purista" -y parece que en Puerto Rico esta palabra ha perdido todas sus acepciones, menos la despectiva. Mucho me temo, sin embargo, que mi respuesta a lo dicho por Rubén del Rosario se base sobre todo en la observación y la experiencia personales. No tengo a la mano estadísticas que me permitan justificar una tesis, pero creo que ciertas comparaciones entre México y Puerto Rico serían muy reveladoras.

La presión económica de los Estados Unidos que soporta México es tan fuerte como la que sufre Puerto Rico. Sin embargo, cuando uno viaja de México a Puerto Rico no puede menos de comprobar, desde el primer momento, que la influencia del inglés sobre el español es aquí muchísimo más marcada. En las calles de San Juan, sería difícil encontrar a alguien capaz de terminar una frase exclusivamente en español. Y lo más inquietante es que también padecen de este achaque muchos profesores universitarios.

Existen algunas diferencias de bastante importancia entre México y Puerto Rico por lo que toca a los anglicismos - sin contar con que en Puerto Rico éstos son más frecuentes y más generales:

I) Desde el punto de vista del léxico, los mexicanos suelen hispanizar sus adaptaciones; los puertorriqueños, en cambio, traspasan a su lengua las voces tal como las encuentran en inglés; pero precisamente por la debilidad del consonantismo isleño, esas palabras quedan casi irreconocibles, tanto para los angloparlantes como para los hispanohablantes que no pertenecen a la zona del Caribe.

2) En cuanto a la sintaxis, el español de Puerto Rico se va transformando de día en día, mientras que la sintaxis mexicana, fuera de una que otra corrupción, ha quedado básicamente incólume. 3) Aunque la economía mexicana depende en gran parte de los Estados Unidos, México es un estado independiente, lo ha sido durante mucho tiempo, y a menudo, a lo largo de su historia, ha luchado para seguir siéndolo. No es éste, desgraciadamente, el caso de Puerto Rico.

4) En México, las esferas intelectuales fijan normas de lenguaje culto, lo cual permite que se desarrolle una conciencia lingüística entre los estudiantes de las escuelas y universidades. Yo tengo la 
impresión de que en Puerto Rico hay pocas normas de esta índole, y de que ni siquiera se reconoce la necesidad de su existencia; a causa de ello -me duele decirlo-, no hay conciencia lingüística de ninguna especie en las escuelas.

5) En México hay un núcleo bastante numeroso de la población instruida que lucha constantemente contra la adopción de anglicismos. En Puerto Rico, ya no hay casi nadie que siga combatiendo. Algunos de los lingüistas puertorriqueños - tal es, por lo menos, mi impresión- han sido como falsos profetas, que han llegado a convencer a sus compatriotas de que es "progresista" absorber cuantos anglicismos se ofrezcan, y que es decadente y estúpido el tratar siquiera de combatirlos.

Huelga decir que la batalla contra la adopción de formas extranjeras es una batalla que no se gana nunca, y que nadie espera ganar. Los cambios lingüísticos ocurrirán, quiérase o no, siempre que existan presiones económicas y sociales que los favorezcan. Las Academias de la Lengua y los puristas sirven a manera de freno que suele entorpecer el proceso de absorción a la vez que comunican a la población una fuerte conciencia lingüística, ayudando de este modo a conservar la integridad del idioma. Creo, con toda sinceridad y con todo el cariño que siento por la isla de Puerto Rico y por mis amigos y colegas puertorriqueños, que éste es el principal problema lingüístico actual de la Isla, y el que las personas cultas y conscientes deben tratar de resolver si no quieren acabar hablando un patois empobrecido e híbrido. He observado, como muchas otras personas, que los puertorriqueños que mejor hablan el español suelen ser los mismos que mejor hablan el inglés. Esto, para cualquier país bilingüe, es razonable y lógico. Si a la población se le da una conciencia firme y una orientación sana en cuanto a los procesos lingüísticos de su lengua nativa, es seguro que mejorará a la vez su dominio sobre el otro idioma.

Joseph H. MatLuck

The University of Texas. 